\title{
Improving equipment effectiveness by designing optimal production process.
}

\begin{abstract}
Reliable manufacturing equipment is an indispensable factor to the performance and profitability of manufacturing systems. Total productive maintenance (TPM) has been recognized as a comprehensive manufacturing strategy to maximize equipment reliability and effectiveness through rooting out all manufacturing losses. Availability of equipment is a focus area in TPM to improve effectiveness throughout the lifetime of the equipment. This study develops a mixed integer linear programming model to increase equipment availability considering maintenance cost of each machine in the system. The main objective is minimizing total cost while designing optimal material flows between different operational levels of manufacturing process. A hypothetical problem is presented and solved by the developed model.
\end{abstract}

Keyword: Productive maintenance; Mathematical programming; Availability; Overall equipment effectiveness. 